\title{
Validasi Nilai Erosivitas Hujan Dari Data Penginderaan Jauh TRMM 3B42 Di Bali Selatan
}

\author{
I Wayan Sandi Adnyana12 dan Abd. Rahman As-syakur1* \\ 1Environmental Research Center (PPLH), Udayana University, \\ Jalan PB Sudirman, Denpasar, Bali, 80232 Indonesia \\ 2Faculty of Agriculture, Udayana University, \\ Kampus Bukit Jimbaran, Bali, 80361Indonesia \\ *Email: ar.assyakur@pplh.unud.ac.id
}

\begin{abstract}
Rainfall erosivity is a measure for the erosive force of rainfall. Rainfall kinetic energy determines the erosivity and is in turn greatly dependent on rainfall intensity. Research has been conducted to validate monthly rainfall erosivity derived from the Tropical Rainfall Measuring Mission (TRMM) Multisatellite Precipitation Analysis (TMPA) 3B43 version 7 using rain gauge data analysis from 2003 to 2012. Rain gauge located in the south Bali regions were employed to monitor erosivity value from two different methods that are base on Bols (1978) and Abdurachman (1989). The relationship of erosivity and their other factor from TRMM 3B43 and rain gauge data statistical analysis measures consisted of the linear correlation coefficient, the mean bias error (MBE), and the root mean square error (RMSE). Data validation was conducted with point-by-point analysis. The results of these analyses indicate that satellite data have lower values than the gauge estimation values. The point-by-point analysis indicated satellite data values of high to very high correlation, while values of MBE and RMSE tended to indicate underestimations with high square errors. Moreover, monthly rainfall erosivity derived from TRMM give high correlation from both methods, with has high bias and root-mean-square error. In general, the data from TRMM 3B43 version 7 are potentially usable to replace rain gauge data based on erosivity estimation, but after inconsistencies and errors are taken into account.
\end{abstract}

Keywords: TRMM 3B43; erosivity; rainfall; remote sensing

\section{Pendahuluan}

Di daerah beriklim tropika basah, air merupakan penyebab utama erosi tanah, sedangkan angin tidak mempunyai pengaruh yang berarti. Proses erosi oleh air rnerupakan kombinasi dua sub proses yaitu penghancuran struktur tanah menjadi butir-butir primer oleh energi tumbuk butir-bitir hujan yang menimpa tanah dan perendaman oleh air yang tergenang (proses dispersil), dan pemindahan (pengangkutan) butir-butir tanah oleh percikan hujan, penghancuran struktur tanah diikuti pengangkutan butir-butir tanah tersebut oleh air yang mengalir di permukaan tanah (Arsyad, 1989). Tenaga pendorong yang menyebabkan terkelupas dan terangkutnya partikel-partikel tanah ke tempat yang lebih rendah dikenal sebagai erosivitas hujan (Sukoco, 2010).
Perkiraan besar erosi tanah menggunakan formula Universal Soil Loss Equation (USLE) membutuhkan indeks erosivitas hujan yang diperkirakan menggunakan data hujan (Mujiharjo, 2001). Dalam perhitungan perkiraan besaran erosi dengan metode USLE di Indonesia, faktor erosivitas hujan adalah salah satu faktor paling sulit diprediksi karena kekurangan data hujan dari pos pengamat hujan otomatis serta variabilitas hujan di Indonesia yang sangat tinggi. Oleh karena itu, beberapa penghitungan erosivitas hujan (Faktor R) dikembangkan di Indonesia karena kebanyakan data hujan yang tersedia di Indonesia hanyalah data yang diperoleh dari Ombrometer, sedangkan aslinya USLE memanfaatkan data hujan yang diperoleh secara otomatis (Sulistyo, 2011). 
Di Indonesia, penilaian faktor $\mathrm{R}$ masih menggunakan data-data hujan yang diperoleh dari Badan Meteorologi, Klimatologi dan Geofisika (BMKG) dengan keberadaan yang masih cukup jarang pada wilayah pegunungan sehingga perlu diinterpolasi dengan teknolgi SIG untuk mendapatkan sebaran spasialnya (Nuarsa, 1998; Sulistyo et al., 2009; ). Sementara itu, di luar Indonesia penilaian faktor $\mathrm{R}$ sudah memulai menggunakan data penginderaan jauh. Di Afrika, Vrieling et al. (2010) sudah menggunakan data hujan dari citra satelit Tropical Rainfall Measuring Mission (TRMM) 3B43 untuk mengestimasi erosivitas hujan dan hasil validasi menunjukan tingkat korelasi yang tinggi dengan data lapangan. Aplikasi data TRMM di indonesia masih sebatas digunakan untuk kepentingan klimatologi seperti pemetaan dampak Madden-Julian Oscillation (MJO) terhadap curah hujan (Hidayat and Kizu, 2010), pemetaan variabilitas hujan (As-syakur et al., 2013), pemetaan daerah rawan kekeringan klimatologis (Vernimmen et al., 2012; Nuarsa dkk., 2015), pemetaan dampak El Niño-Southern Oscillation (ENSO) dan Indian Ocean Dipole (IOD) terhadap hujan (As-syakur et al., 2014), dan pemetaan dampak Monsun, topografi dan ENSO Modoki terhadap veriabilitas hujan di Indonesia (As-syakur et al, 2016). Akan tetapi dalam perkembangannya, data hujan dari data penginderaan jauh TRMM belum pernah diaplikasikan untuk memprediksi erosi di Indonesia, sehingga perlu dilakukan penelitian untuk mengetahui tingkat keakurasian data TRMM dalam menghitung erosivitas hujan di Indonesia, khususnya di wilayah Bali Selatan.

Produk Tropical Rainfall Measuring Mission (TRMM) Multisatellite Precipitation Analysis (TMPA) merupakan produk hasil gabungan antara TRMM Precipitation Radar (PR) dan TRMM Microwave Imager (TMI) beserta citra meteorologi Microwave dan Infrared lainnya (Huffman et al., 2007). TMPA terbagi dalam 2 tipe data yaitu tipe 3B42 yang merupakan data kombinasi per 3 jam dan tipe 3B43 yang merupakan kombinasi bulanan. TMPA 3B43 telah digunakan untuk berbagai aplikasi termasuk diantaranya adalah pemantauan cuaca/iklim, analisis iklim, verifikasi model numerik, dan studi hidrologi (Xie et al., 2007). Hasil penelitian sebelumnya di Indonesia menunjukkan bahwa hubungan antara TMPA dengan data lapangan dari Badan Meteorologi, Klimatologi, dan Geofisika (BMKG) adalah kuat khususnya terhadap pola hujan bulanan (As-syakur et al., 2010; Suryantoro dkk., 2008) walaupun masih dalam kondisi dibawah estimasi data hujan BMKG (As-syakur et al., 2010). Secara umum tujuan dibuatnya produk TMPA telah mencapai sasaran yang diinginkan yaitu penyediaan data hujan bulanan dengan sebaran yang meliputi darat dan lautan serta sesuai dengan keadaan sebenarnya yang ditunjukkan oleh hasil-hasil penelitian sebelumnya (seperti Assyakur et al., 2010; Feidas, 2010; Chokngamwong and Chiu, 2008; Mehta and Yang, 2008; Su et al., 2008; Islam and Uyeda, 2007; Wolff et al., 2005). Data TMPA, khususnya tipe 3B43 merupakan data yang selalu tersedia setelah bulan pengamatan (up to date). Kondisi ini memungkinkan dimanfaatkannya data TRMM untuk memantau kondisi hujan secara cepat, baik itu besaran curah hujan maupun kondisi anomali curah hujan.

Penelitian ini bertujuan untuk mengetahui tingkat keakurasian data hujan yang diperoleh dari TMPA 3B43 untuk menghitung erosivitas hujan di Bali Selatan. Erosivitas hujan dihitung dengan dua persamaan umum yang sering digunakan di Indonesia yaitu persamaan Bols (1978) dan Abdurachman (1989). Hasil perhitungan erosivitas hujan dari data satelit selanjutnya dikomparasikan dengan data dari Badan Meteorologi, Klimatologi, dan Goefisika (BMKG) untuk mengetahui tingkat keakuratannya. Berdasarkan penelitian ini diharapkan dapat diketahui besaran eror dan validitas data penginderaan jauh dalam pengaplikasiannya untuk memprediksi erosi tanah di Provinsi Bali pada khususnya dan Indonesia pada umumnya.

\section{Data and Analysis}

\subsection{Lokasi dan Data}

Dearah cakupan penelitian meliputi wilayah Bali Selatan. Data hujan lapangan yang digunakan dalam penelitian ini adalah data yang diperoleh dari stasiun pengamatan hujan otomatis Stasiun Geofisika Kelas II Balai Meteorologi, Klimatologi, dan Geofisika (BMKG) Sanglah, Denpasar-Bali. Mengingat sulitnya memperoleh data hujan lapangan dan terbatasnya stasiun pengamatan hujan otomatis di wilayah Bali Selatan, maka dalam penelitian ini data hujan lapangan yang diperoleh dari Stasiun Geofisika Sanglah diasumsikan dapat mewakili kondisi Bali Selatan. 
Adapun nilai hujan dari penginderaan jauh diperoleh dari data TRMM 3B43 versi 7 yang dianalisis mulai dari bulan Januari 2003 sampai Desember 2012 atau selama 10 tahun pengamatan. Satelit TRMM adalah misi pengamatan curah di wilayah tropis yang disponsori oleh NASA (National Aeronautics and Space Administration) dan JAXA (Japan Aerospace Exploration Agency, yang dulu di sebut NASDA-National Space Development Agency), dan telah mengumpulkan data dari November 1997 sampai saat ini (Kummerow et al., 2000). TRMM merupakan program penelitian jangka panjang yang didesain untuk studi tentang tanah, laut, udara, es, dan sistem total kehidupan di Bumi (Islam and Uyeda, 2007). Satelit TRMM memiliki 5 sensor yaitu PR (Precipitation Radar), TMI (TRMM Microwave Imager), dan VIRS (Visible and Infrared Scanner), CERES (Clouds and the Earth's Radiant Energi System), dan LIS (Lightning Imaging Sensor). TRMM berorbit polar (non-sunsynchronous) dengan inklinasi sebesar $35^{\circ}$ terhadap ekuator, berada pada ketinggian orbit $350 \mathrm{~km}$ (pada saat-saat awal diluncurkan), dan diubah ketinggian orbitnya menjadi 403 km sejak 24 Agustus 2001 sampai sekarang. TRMM memiliki tiga level produk, yaitu level 1 sampai 3. TRMM 3B43 merupakan bagian dari TMPA dan berada tingkatan produk level 3 dari kombinasi data TRMM dengan data lainnya. TMPA adalah data kalibrasi berbasis skema berurut yang mengkombinasikan perkiraan hujan dari beberapa jenis satelit dan data penakar hujan. TMPA menyediakan cakupan data hujan global pada sabuk lintang $50^{\circ} \mathrm{LU}$ sampai $50^{\circ} \mathrm{LS}$ dengan resolusi spasial $0.25^{\circ} \times 0.25^{\circ}$ serta resolusi temporal tiga jam-an untuk TRMM 3B42 dan resolusi temporal bulanan untuk TRMM 3B43 (Huffman et al., 2007; Huffman et al., 2010). Algoritma yang digunakan untuk menghasilkan data TMPA didasarkan pada teknik dari Huffman et al. (1995, 1997) dan Huffman (1997). Data TRMM3B43 diperoleh dari website ftp://disc2.nascom.nasa.gov/ data/s4pa/TRMM_L3/.

\subsection{Analisis Data}

Erosivitas (R) hujan adalah daya erosi hujan pada suatu tempat. Nilai erosivitas hujan dapat dihitung berdasarkan data hujan yang diperoleh dari penakar hujan otomatis atau dari penakar hujan biasa. Dalam penelitian ini, dua metode digunakan untuk menghitung erosivitas hujan yang bertujuan untuk mengetahui metode yang paling metode tersebut adalah Bols (1978) dan Abdurachman (1989). Metode perhitungan Bols (1978) yang digunakan dalam untuk menentukan tinggkat erosivitas hujan dalam penelitian ini adalah dihitung dengan menggunakan persamaan:

$$
\mathrm{R}=6,119 \times(\mathrm{P})^{1,21} \times(\mathrm{D})^{-0,47} \times(\mathrm{M})^{0,53}
$$

Sementara itu, nilai erosivitas hujan dari metode Abdurachman (1989) dihitung dengan persamaan:

$$
\mathrm{R}=\frac{(\mathrm{P})^{2,263} \times(\mathrm{M})^{0,678}}{40,056 \times(\mathrm{D})^{0,349}}
$$

dimana $\mathrm{R}$ adalah indeks erosivitas rata-rata bulanan (MJ mm ha-1 hr-1 yr-1), P adalah curah hujan bulanan (cm), D adalah jumlah hari hujan bulanan, dan M adalah curah hujan maksimum selama 24 jam dalam satu bulan $(\mathrm{cm})$.

Untuk mengetahui tingkat keakuratan hasil analisis data TMPA, maka hasil analisis data TMPA di komparasikan dengan data dari BMKG. Data yang yang akan dikomprasikan berupa data curah hujan bulanan, jumlah hari hujan bulanan, curah hujan maksimum selama 24 jam dalam satu bulan, serta nilai erosivitas hujan dari metode Bols (1978) dan Abdurachman (1989). Untuk mengetahui tinggi rendahnya tingkat keakuratan, data-data dianalisis dengan statistik berupa analisis tingkat korelasi (r), rata-rata bias eror (mean bias eror; MBE), dan akar rata-rata kuadrat kesalahan (root mean square error; RMSE). Untuk mendapatkan nilai koreleasi, MBE dan RMSE, maka dalam proses perhitungannya menggunakan persamaan berikut (von Storch and Zwiers, 1999; Feidas, 2010):

$$
\mathrm{r}=\frac{\sum_{i=1}^{\mathrm{n}}\left(S_{i}-\bar{S}\right)\left(G_{i}-\bar{G}\right)}{(\mathrm{n}-1) \sigma_{S} \sigma_{G_{i}}}
$$

$$
\begin{aligned}
\mathrm{RMSE} & =\sqrt{\left(\frac{1}{n} \sum_{i=1}^{\mathrm{n}}\left(S_{i}-\mathrm{MBE}-G_{i}\right)^{2}\right)} \\
\mathrm{MBE} & =\frac{1}{n} \sum_{i=1}^{n}\left(S_{i}-G_{i}\right)
\end{aligned}
$$


I Wayan Sandi Adnyana, dkk. : Validasi Nilai Erosivitas Hujan dari Data Penginderaan Jauh.....

Dimana Si adalah nilai hujan dari TMPA, Gi nilai hujan dari BMKG, ?S dan ?G adalah standard deviasi dari kedua data hujan dan $\mathrm{n}$ adalah panjang bulan data curah hujan. Dari sudut pandang statistik, analisis korelasi digunakan untuk menggambarkan hubungan statistik linear antara dua variabel acak, dimana hal ini menunjukkan sepasang variabel yang berbeda bervariasi sama persis, satu variabel yang terkait dengan yang lain dapat diskalakan dalam bentuk positif atau negatif (von Storch and Zwiers, 1999). Semua nilai analisis statistik dipresentasikan dengan nilai persen (\%), kecuali nilai korelasi linier.

\section{Hasil dan Pembahasan}

Gambar 1 mempresentasikan nilai-nilai statistik parameter-parameter perhitungan erosivitas hujan dan hasil perhitungan erosivitas hujan dari kedua metode berdasarkan perbandingan data TRMM dan BMKG selama 10 Tahun. Hasil analisis menunjukan bahwa nilai hubungan antara TRMM dengan data BMKG untuk mengetahui nilai curah hujan bulanan, jumlah hari hujan bulanan, dan curah hujan maksimum selama 24 jam dalam satu bulan menunjukan tingkat korelasi sangat tinggi sampai tinggi. Sedangkan, nilai hubungan hasil perhitungan erosivitas hujan dari dua metode yang digunakan menunjukan tingkat korelasi yang tinggi. Komparasi nilai curah hujan bulanan dari data TRMM dengan BMKG menunjukan nilai korelasi yang sangat tinggi mencapai 0,87 . Kondisi yang sama juga diperlihatkan oleh tingkat korelasi dari data jumlah hari hujan bulanan yang nilai korelasi yang mencapai 0,83 . Sementara itu, curah hujan maksimum selama 24 jam dalam satu bulan menunjukan kondisi korelasi yang lebih rendah dibandingkan dengan nilai curah hujan bulanan dan jumlah hari hujan bulanan, yaitu dengan kelas korleasi yang tinggi $(r=0,68)$. Nilai korelasi antara erosivitas hujan hasil perhitungan data TRMM yang dibandingkan dengan hasil perhitungan dari data BMKG menunjukan korelasi yang tinggi untuk kedua hasil perhitungan. Dimana hasil perhitungan erosivitas hujan dengan metode Bols lebih besar dibandingkan dengan hasil perhitungan metode Abdurachman yaitu dengan nilai $\mathrm{r}=0,79$ untuk metode Bols dan 0,76 untuk metode Abdurachman.

Nilai RMSE hasil analisis juga menunjukan kondisi eror yang tinggi dari data TRMM 3B43 dalam kemampuannya menghitung erosivitas hujan di Bali Selatan. Secara umum, nilai RMSE paling rendah diperoleh dari parameter jumlah hari hujan bulanan. Sedangkan hasil perhitungan erosivitas hujan dari kedua matode yang diaplikasi juga menunjukan nilai RMSE yang sangat tinggi yaitu lebih besar dari 50\% dari data hujan yang diperoleh dari BMKG. Secara statistik, bila nilai RMSE memlebihi 50\% dari data lapangan, maka data satelit tersebut tidak cukup dapat digunakan untuk menggati data lapangan.
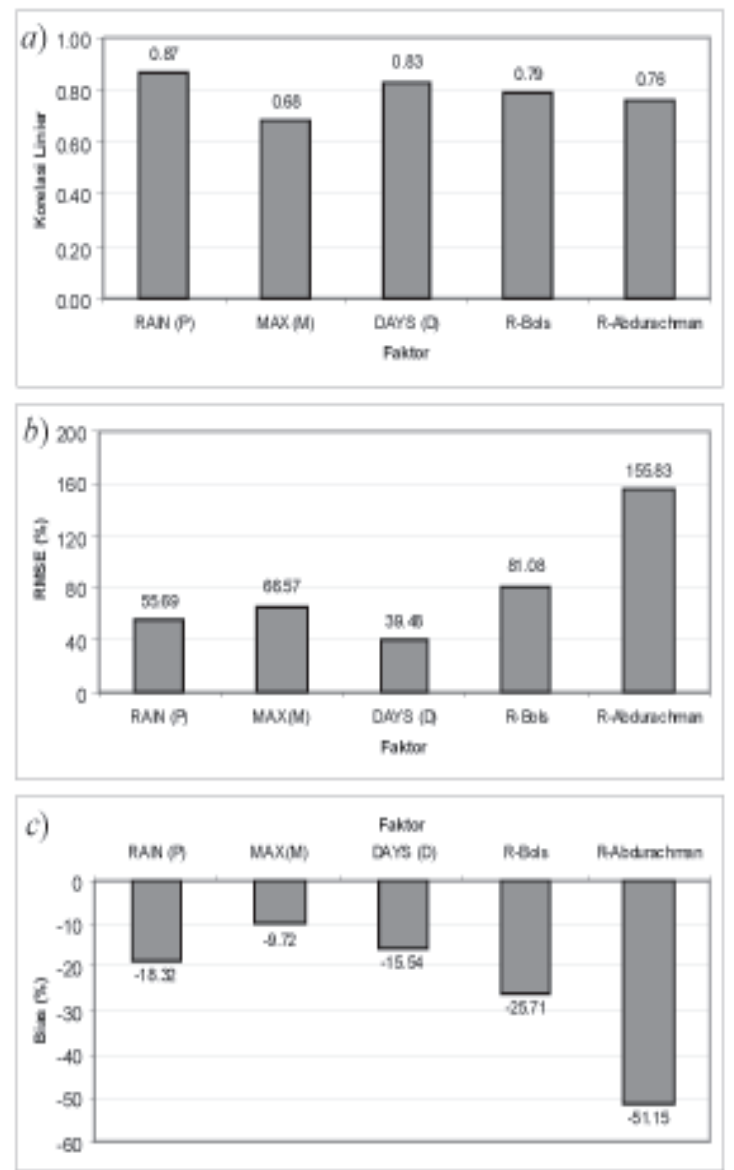

Gambar 1. Grafik statistik parameter-parameter perhitungan erosivitas hujan dan hasil perhitungan erosivitas hujan dari kedua metode berdasarkan perbandingan data TRMM dan BMKG selama 10 Tahun: (a) nilai korelasi linier; (b) RMSE; dan (c) bias eror.

Hasil analisis bias eror secara umum memperlihatkan semua paremater yang dianalisis memperlihatkan kondisi dibawah estimasi data BMKG, seperti yang terlihat pada Gambar 1(c). Sementara 

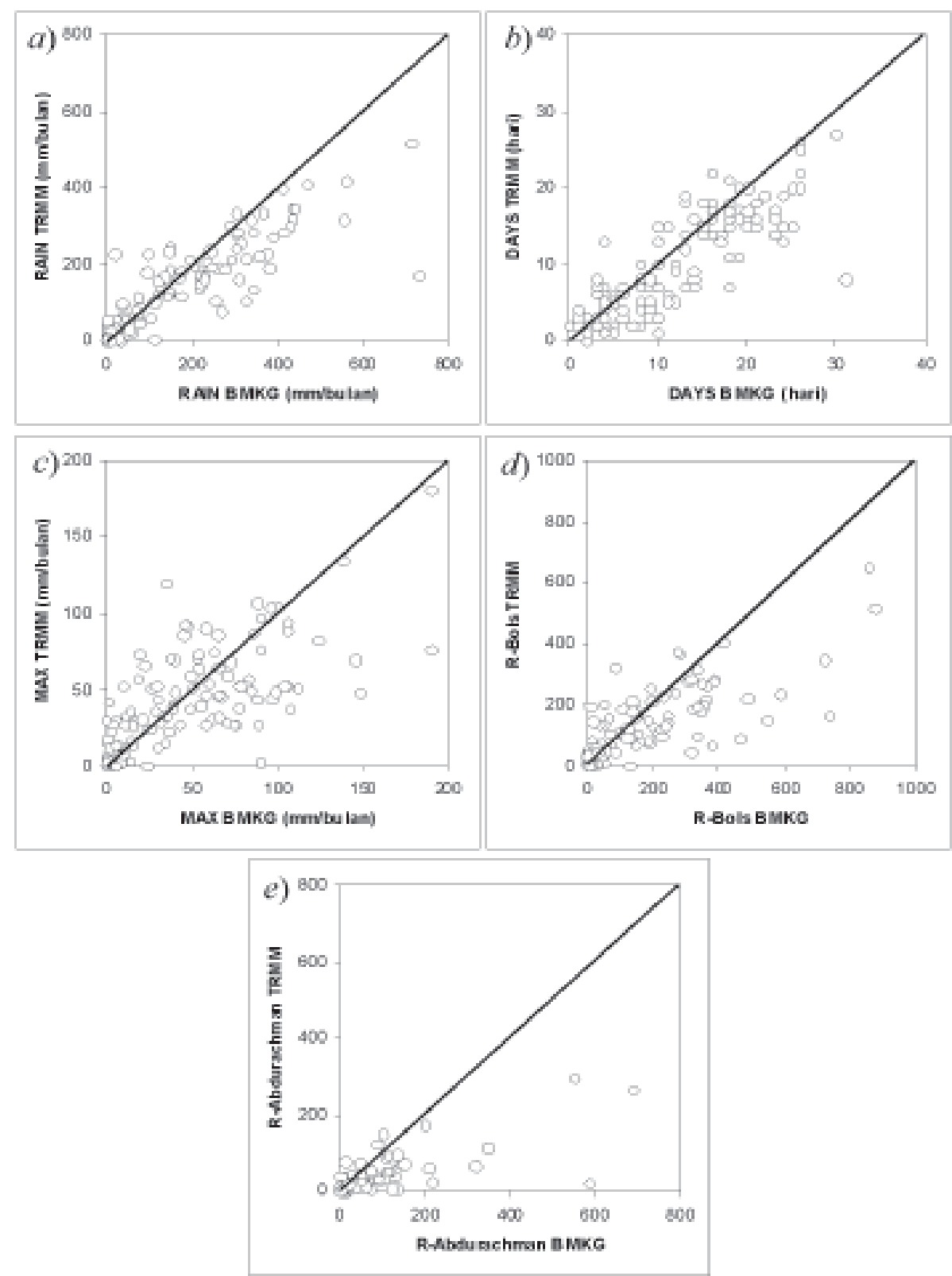

Gambar 2. Scatterplot antara varibilitas hujan pada perhitungan erosivitas dan nilai erosivitas dari data TRMM 3B42 dengan data BMKG dalam kurun waktu 10 Tahun (2003-2012): (a) nilai curah hujan bulanan, (b) jumlah hari hujan bulanan, (c) curah hujan maksimum selama 24 jam dalam satu bulan, (d) nilai erosivitas hujan dari metode Bols (1978), dan (e) nilai erosivitas hujan dari metode Abdurachman (1989).

itu, Gambar 2 dengan jelas menunjukan bahwa nilai parameter-parameter perhitungan erosivitas hujan dan hasil perhitungan erosivitas hujan sebagian besar berada di bawah garis linier sempurna yang menjelaskan nilai-nilai parameter perhitungan erosivitas hujan dan hasil perhitungan erosivitas hujan dari data TRMM 3B43 berada dibawah nilai estimasi data BMKG. Perhitungan statistik memperlihatkan bahwa nilai korelasi tidak berbanding lurus dengan nilai bias eror, seperti nilai curah hujan 

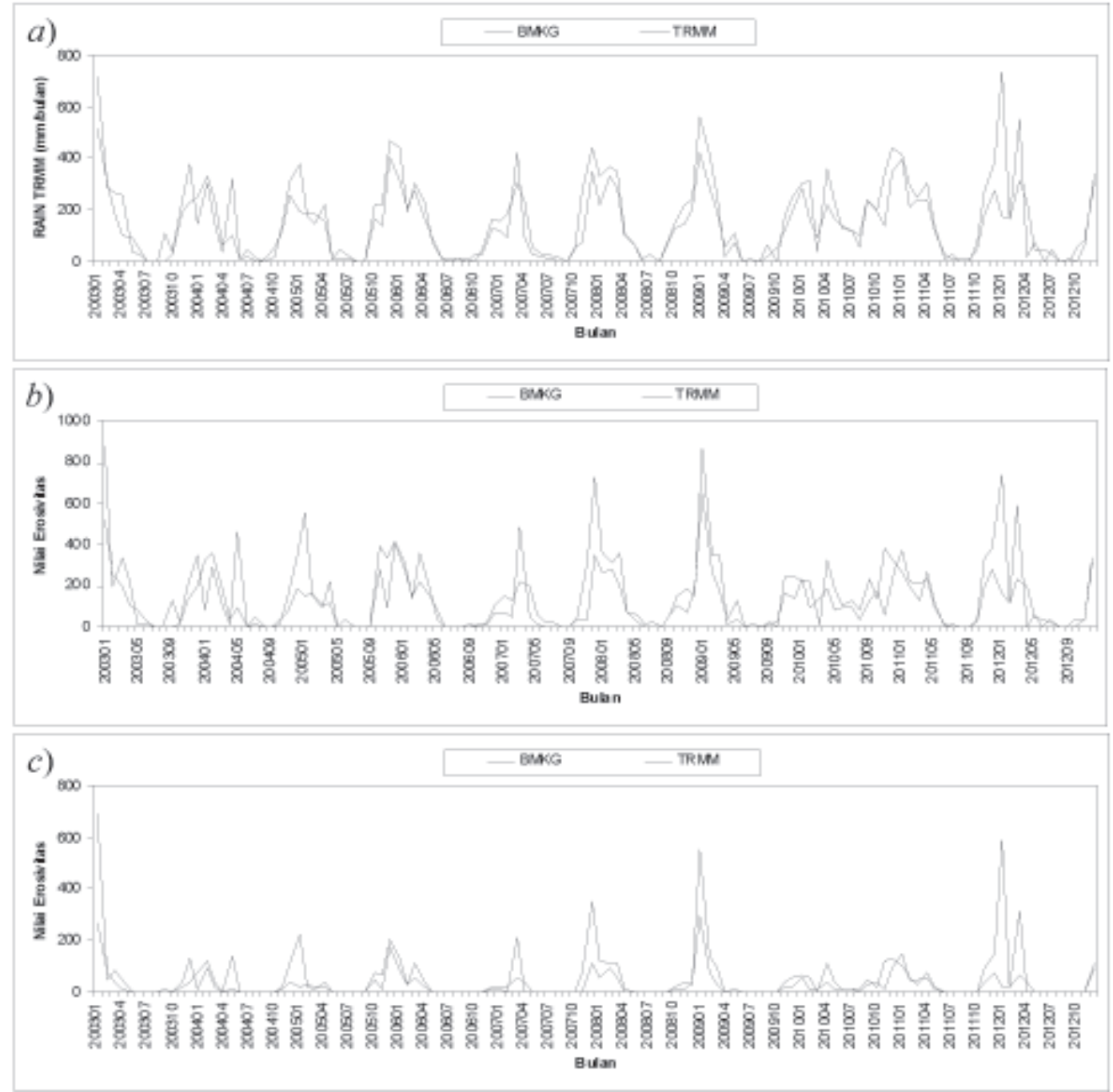

Gambar3. Grafik time-series perbandingan data hujan dan nilai erosivitas selama kurun waktu 10 tahun (2003-2012) dari data TRMM dan BMKG: (a) nilai curah hujan bulanan, (b) nilai erosivitas hujan dari metode Bols (1978), dan (c) nilai erosivitas hujan dari metode Abdurachman (1989).

maksimum selama 24 jam dalam satu bulan memperlihatkan kondisi korelasi yang paling rendah dibandingkan dengan paramater yang lain, akan tetapi nilai bias erornya memperlihatkan kondisi yang paling baik yaitu $-9,72 \%$. Kondisi yang sama juga terlihat pada nilai curah hujan bulanan, dimana nilai bias erornya memperlihatkan nilai yang paling buruk dibandingkan dengan tiga parameter lainnya yaitu 18,32, walaupun nilai korelasi memperlihatkan nilai yang paling baik. Sementara itu, nilai bias eror hasil perhitungan erosivitas hujan dari metode Bols dan
Abdurachman memperlihatkan kondisi yang serupa, yaitu berada kondisi yang dibawah estimasi perhitungan dari data BMKG. Nilai erosivitas data TRMM hasil perhitungan dengan metode Bols memperlihatkan kondisi yang lebih baik dibandingkan dengan hasil perhitungan dengan metode Abdurachman.

Kondisi bias eror yang cukup baik dari data TRMM dalam kemampuannya menghitung erosivitas hujan kemungkinan terjadi karena ketidakmampuan data TRMM mengestimasi puncak-puncak nilai 
erosivitas hujan saat kejadian intensitas hujan tinggi. Seperti yang terlihat pada Gambar 3, bias eror yang paling tinggi terjadi pada pucak-puncak musim hujan. Pada Gambar 3(a) terlihat bahwa perbedaan nilai hujan antara data TRMM dengan data BMKG pada saat hujan lebat terjadi sebenarnya tidak terlalu besar, akan tetapi setelah dihitung nilai erosivitas hujan dengan persamaan Bols dan Abdurachman, nilai puncak erosivitas hujan berbeda cukup besar. Kondisi ini mungkin terjadi selain akibat nilai hujan, kemungkinan juga akibat akumlasi dari bias eror dari data-data jumlah hari hujan bulanan dan curah hujan maksimum selama 24 jam dalam satu bulan.

\section{Simpulan}

Validasi data erositas hujan dan data-data komponen pendukungnya dari data TRMM telah dilakukan di Bali Selatan. Data bulanan TRMM 3B43 versi 7 selama 10 Tahun pengamatan dari bulan Januari 2003 sampai Desember 2012 digunakan dalam penelitian. Data TRMM yang dianalisis divalidasi keakurasiannya dengan membandingkan hasil analisis erosivitas dari data TRMM dengan hasil analisis erosivitas dari data BMKG. Dari hasil analisis menunjukan bahwa data TRMM bisa diaplikasi untuk menghitung erosivitas hujan pada wilayah yag tidak memiliki data hujan BMKG, dengan catatan bahwa data hujan TRMM telah dihilangkan dan diminimalisir eror-eror yang dihasilkan. Nilai-nilai statistik perbandingan antara data TRMM dengan BMKG dalam menganalisis parameter-parameter perhitungan erosivitas hujan dan hasil perhitungan erosivitas hujan dari kedua metode memiliki kondisi yang sanat baik sampai sedang. Nilai-nilai korelasi menampilkan kondisi kuat sampai sangat kuat. Tetapi kondisi RMSE cukup baik dangan nilai bias eror dari sangat baik sampai sedang. Secara umum, metode Bols memiliki tingkat keakurasian yang lebih baik dibandingkan dengan metode Abdurachman dengan level korelasi yang lebih baik serta RMSE dan bias eror yang lebih rendah.

\section{Daftar Pustaka}

Sukoco. (2010). Pemetaan Erosivitas Hujan Dengan Sistem Informasi Geografis. Journal Speed Sentra Penelitian Engineering dan Edukasi, 2(2), $1-5$.
Arsyad, S. (1989). Konservasi Tanah dan Air. BogorIndonesia: IPB Press.

Mujiharjo, S. (2001). Kemungkinan pemanfaatan limbah pencucian batubara sebagai sumber energi alternatif dalam rumah tangga dan industri kecil melalui proses pembriketan. Jurnal Penelitian Lembaga Penelitian UNIB, 7(2), 185190.

Sulistyo, B. (2011). Pengaruh erosivitas hujan yang diperoleh dari rumus yang berbeda terhadap pemodelan erosi berbasis raster (Studi Kasus Di DAS Merawu, Banjarnegara, Jawa Tengah). Agritech, 31(3), 250-259.

Nuarsa, I. W. (1998). Penggunaan Analisis Citra Digital dan Sistem Informasi Geografi untuk Prediksi Besarnya Erosi di DAS Ayung Bagian Hilir Kabupaten Badung Propinsi Bali (Master thesis). Jogjakarta-Indonesia: Universitas Gadjah Mada.

Sulistyo, B., Gunawan, T., Hartono, H., \& Danoedoro, D. (2011). Pemetaan Faktor C Yang Diturunkan Dari Berbagai Indeks Vegetasi Data Penginderaan Jauh Sebagai Masukan Pemodelan Erosi Di DAS Merawu. Jurnal Manusia dan Lingkungan, 18(1), 68-78.

Sulistyo, B., Gunawan, T., \& Danoedoro, P. (2009). Toward a fully and absolutely raster-based erosion modeling by using RS and GIS. Indonesian Journal of Geography, 41(2), 149-170.

Vrieling, A., Sterk, G., \& de Jong, S. M. (2010). Satellite-based estimation of rainfall erosivity for Africa. Journal of hydrology, 395(3), 235-241.

Hidayat, R., \& Kizu, S. (2010). Influence of the Madden-Julian Oscillation on Indonesian rainfall variability in austral summer. International Journal of Climatology, 30(12), 1816-1825.

As-syakur, A.R., T. Tanaka, R. Prasetia, I.K. Swardika, and I.W. Kasa. 2010. Comparison of TRMM Multisatellite Precipitation Analysis (TMPA) products and daily-monthly gauge data over Bali Island. International Journal of Remote Sensing, In Press. Accepted on 23 August 2010.

As-syakur, A. R., Tanaka, T., Osawa, T., \& Mahendra, M. S. (2013). Indonesian rainfall variability ob- 
servation using TRMM multi-satellite data. International journal of remote sensing, 34(21), $7723-7738$

Vernimmen, R. R. E., Hooijer, A., Aldrian, E., \& van Dijk, A. I. J. M. (2012). Evaluation and bias correction of satellite rainfall data for drought monitoring in Indonesia. Hydrology and Earth System Sciences, 16(1), 133-146.

Nuarsa, I. W., Adnyana, I., \& As-syakur, A. R. (2015). Pemetaan Daerah Rawan Kekeringan Di BaliNusa Tenggara Dan Hubungannya Dengan ENSO Menggunakan Aplikasi Data Penginderaan Jauh. Bumi Lestari, 15(1), 20-30.

As-syakur, A., Adnyana, I., Mahendra, M. S., Arthana, I. W., Merit, I. N., Kasa, I. W., Ekayanti, N. W., Nuarsa, I. W., \& Sunarta, I. N. (2014). Observation of spatial patterns on the rainfall response to ENSO and IOD over Indonesia using TRMM Multisatellite Precipitation Analysis (TMPA). International Journal of Climatology, 34(15), 38253839.

As-syakur, A. R., Osawa, T., Miura, F., Nuarsa, I. W., Ekayanti, N. W., Dharma, I. G. B. S., Adnyana, I.
W. S., Arthana, I. W., \& Tanaka, T. (2016). Maritime Continent rainfall variability during the TRMM era: the role of monsoon, topography and El Niño Modoki. Dynamics of Atmospheres and Oceans, 75, 58-77.

Huffman, G.J., R.F.Adler, D.T. Bolvin, G. Gu, E.J. Nelkin, K.P. Bowman, Y. Hong, E.F. Stocker, and D.B. Wolff. 2007. The TRMM Multisatellite Precipitation Analysis (TMPA): quasi-global, multiyear, combined-sensor precipitation estimates at fine scales. Journal of Hydrometeorology, 8(1). 3855 .

Xie, P., A. Yatagai, M. Chen, T. Hayasaka, Y. Fukushima, C. Liu, and S. Yang. 2007. A gaugebased analysis of daily precipitation over East Asia. Journal of Hydrometeorology, 8. 607-626.

As-Syakur, A. R., Tanaka, T., Prasetia, R., Swardika, I. K., \& Kasa, I. W. (2011). Comparison of TRMM multisatellite precipitation analysis (TMPA) products and daily-monthly gauge data over Bali. International journal of remote sensing, 32(24), 8969-8982. 